\title{
Will the Chinese Economy Be More Volatile in the Future? Insights from Urban Household Survey Data
}

Jian Yu, Xunpeng Shi*, and James Laurenceson

\begin{abstract}
Consumption volatility is a key source of economic growth volatility and thus is an important factor in designing macroeconomic policy. Using urban household survey data over the period 2002-2009 in 18 provinces in China, this paper investigates the factors that determine household consumption volatility with both a traditional variance decomposition method and an advanced variance decomposition method. The traditional variance decomposition suggests that heterogeneity of consumption goods is the key to analyzing consumption volatility in China. Consumption of transportation makes the highest aggregate contribution and per-unit volatility in consumption volatility, while consumption of food makes the second-highest aggregate contribution and the lowest per-unit volatility. Further investigation with the advanced variance decomposition method, which allows us to capture intertemporal dynamics and crosshousehold differences simultaneously, finds that the main factor determining the consumption volatility in China is intertemporal dynamics, rather than cross-household differences. The results suggest that when policy makers design macroeconomic policies to smooth consumption volatility, they should consider heterogeneity in household consumption goods, regional disparity, and intertemporal dynamics simultaneously. Well-managed volatility of Chinese household consumption can contribute to stable economic growth in China and the world.
\end{abstract}

Keywords: consumption volatility; heterogeneity of consumption goods; crosshousehold difference; intertemporal dynamics; China

JEL codes: E21, O11, C22

\footnotetext{
* Jian Yu, Associate Professor, School of Economics, Central University of Finance and Economics, China, email: jianyu@cufe.edu.cn.

Xunpeng Shi (corresponding author), Principal Research Fellow, Australia-China Relations Institute, University of Technology Sydney, NSW 2007, Australia; Visiting Professor, Center of Hubei Cooperative Innovation for Emissions Trading System \& School of Low Carbon Economics, Hubei University of Economics, Wuhan, Hubei Province 430205, China; Senior Research Fellow, Energy Studies Institute, National University of Singapore, 119620 Singapore. email: xunpeng.shi@uts.edu.au.

James Laurenceson, Professor, Australia-China Relations Institute, University of Technology Sydney, NSW 2007, Australia. Email: James.Laurenceson@uts.edu.au.
} 


\section{Introduction}

During China's three decades of reform and opening up, investments, including infrastructure investment and innovation investment, have been the driving force behind China's rapid economic growth (Buckley,2019; Haasis and Liefner, 2019; He et al., 2019; Kim et al., 2019; Sahasranamam and Raman,2018). However, after China's economic development entered the new normal, the economic growth rate has shifted from high speed to medium-high speed. At this time, consumption has become the most important "engine" of China's economic growth (Ansar et al., 2016). Consumption growth is a key driver of economic growth, and volatility in consumption has a detrimental impact on economic growth by creating volatility or uncertainty in economic growth (Amendola et al., 2019; De Giorgi and Gambetti, 2017). China offers a salient example for analyzing consumption volatility. Since China adopted its "new normal" growth model, its economic growth has significantly slowed, and household consumption has played an increasingly important role in economic growth (Chen and Groenewold, 2018; Santaeulàlia-Llopis and Zheng, 2018). During the period 20132018, China's annual economic growth rate fell from $7.1 \%$ to $6.6 \%$, while the share of household consumption in the gross domestic product (GDP) increased from $47 \%$ to $76.2 \%$ (NBS, 2019a). Despite the increase in the share of household consumption, its annual growth rate declined from 11\% in 2011 to 6\% in 2017 (NBS, 2019b). The increasing share and slower growth, compounded by increasing volatility in household consumption, pose additional challenges for the Chinese economy's new growth model. Further studying the driving factors of consumption volatility can shed light on the 
channels of consumption volatility and help design appropriate policies to stabilize consumption and economic growth (Chen, 2017). Because China has become a major force in global economic growth over the past few decades, its growth speed and stability are of global economic interest (Bosworth and Collins, 2008; Zhang, et al, 2019). A less volatile household consumption can contribute to stable economic growth in China and the world.

Whether the Chinese economy will be more volatile has become an interesting issue in academic studies for at least three reasons. First, from a long-term perspective, with the continuous growth of the Chinese economy, an export-driven model is no longer acceptable to the global community and domestic consumption is expected to lead and sustain China's future economic growth. Second, from a short-term perspective, ongoing trade frictions and global industrial relocation put pressure on China's economic growth. A recent study finds that Chinese exports to the Japanese market have been crowded out in all sectors in recent years (Liu et al., 2018). Lastly, a new consumption-driven-growth model needs to be established to sustain China's growth. Additionally, to boost demand, China is also in the process of promoting consumption upgrades by producing new and more valuable goods. This change in the consumption mix could also lead to an unprecedented consumption pattern, including demand and volatility. However, despite the significant amount of literature on consumption volatility in China - such as Chan et al. (2014), Du et al. (2010, 2011), Lai et al. (2014), and Zhao and Hsu (2012) — most of it uses aggregate data at the provincial level, which does not account for the heterogeneity of household 
consumption goods and thus underestimates household consumption volatility.

This paper fills this gap by using China's urban household survey data to assess consumption volatility from the perspectives of heterogeneity in household consumption goods, cross-household differences, and intertemporal dynamics. We make three contributions to the literature. Our first contribution is in demonstrating the contributions of heterogeneity in household consumption goods to consumption volatility. This identifies the goods responsible for the majority of volatility and sheds light on the impact of ongoing consumption upgrades in China on consumption volatility. Our second contribution is in using the advanced variance decomposition method proposed by Crucini and Telmer (2012). This decomposition methodology allows us to examine whether household consumption volatility is due to crosshousehold differences or intertemporal dynamics. This distinction can inform policy designers: if cross-household difference is the key driver, a volatility-smoothing policy should focus on narrowing regional development gaps; on the contrary, if intertemporal dynamics is the key driver, a volatility-smoothing policy should smooth household consumption, which is a driver of economic volatility. Our third contribution is that this paper takes Chinese residents' consumption fluctuations as the starting point to analyze the impact of consumption fluctuations on the future trend of China's economy. The study serves as an important reference for economic development and policy making in other emerging economies that face a similar challenge. It can provide these countries with an important case study about how to deal with consumption volatility, and provide an informed path to consumption upgrading. 
The rest of our paper is organized as follows. Section 2 presents a brief literature review. Section 3 introduces both the traditional and advanced variance decomposition methods. Section 4 discusses data source and stylized facts. Section 5 presents empirical results. Section 6 concludes.

\section{Literature Review}

Consumption volatility is a key source of volatility in economic growth. One of the most basic propositions in macroeconomics is that output volatility can be traced back to supply shocks or demand shocks, in which consumption is a typical demand shock (Amendola et al., 2019; De Giorgi and Gambetti, 2017; Eusepi and Preston, 2015). Many empirical studies to date center on the characteristics and causes of consumption volatility and focus on smoothing consumption in different countries (Giorgi and Gambetti, 2017; Nakamura et al., 2017). Many studies argue that in developing countries an increase in consumption volatility is related to output and income volatility (Dogra and Gorbachev, 2016; Johannes et al., 2016; Sapci, 2017; Zhao and Hsu, 2012). They also find that the level of consumption is less volatile in developed countries than in developing countries and consumption is more volatile than output and income. Boileau and Normandin (2017) review the literature regarding the puzzling large volatility in consumption observed in emerging countries and conclude that in developing countries consumption is $45 \%$ more volatile than output, while in small developed countries it is 3\% less volatile than output. Dogra and Gorbachev (2016) find that consumption volatility among US households increased by around 19\% 
between 1980 and 2004, where the volatility of income rose by $44 \%$. Using a traditional variation decomposition on regional variability in household consumption in G7 countries, Crucini (1999) finds that two-thirds of household consumption growth volatility in the US and Canada can be ascribed to average consumption growth, but the ratio in other G7 countries is less than one-third. Using a volatility decomposition method on the basis of more than two decades of household level consumption data, Hicks (2015) quantifies the impact of changes in marketization on aggregate consumption volatility in both Mexico and the United States.

A lot of literature on consumption volatility discusses consumption risk sharing, which means that idiosyncratic shocks to consumption are diversified away and shared with others (Islamaj and Kose, 2016; Kose and Riezman, 2001; Kydland and Prescott, 1991; Mckay, 2017). Many studies put forward corresponding policy suggestions to achieve consumption risk sharing from the perspectives of the capital market, credit market, financial transfer payment, social security, and social networks (Ang, 2011; Asdrubali et al., 2006; Athanasoulis and Van Wincoop, 2001; Tekin, 2017). Ambrus et al. (2014) propose a model in which connections between individuals serve as social collateral to enforce informal insurance payments and find that social networks help to realize consumption risk sharing. Hevia and Servén (2018) find that rich countries show higher degrees of consumption risk sharing than developing countries, and the gap widens over time.

How volatile is China's household consumption, and what drivers behind the volatility are fundamental research questions in studies on China's household 
consumption and macroeconomic volatility. He et al. (2009) argue that in China detrended consumption is significantly more volatile than detrended output. Zhao and Hsu (2012) find that in China consumption of durables is much more volatile than output, but nondurable consumption is less volatile than output. Chen et al. (2009) reveal a unique long-run cointegration among household consumption, disposable income, financial wealth, and housing wealth, and the majority of variance in the movement of China's urban household consumption is permanent, which is predicted by consumption's classical hypothesis of random-walk behavior. Guo and Huang (2010) find a considerable degree of long-run cointegration and bidirectional causality effects between hot money and business cycle volatility. Tang et al. (2018) investigate the volatility of household consumption in China and find that the structural change in household consumption, which is decreasing in the share of food consumption but increasing in the share of housing consumption, is the main driver that determines the volatility of consumption. Chan et al. (2014) investigate consumption risk sharing in China with provincial data over the period 1952-2008. They find that conventional risksharing analysis without the self-insurance channel tends to overestimate that the degree of risk sharing is around $54 \%$. The degree of provincial risk sharing across China is comparable to that across the OECD countries but falls short of the degree among the states in the US. Xu (2008) finds that more risk-sharing takes place across US states and Canadian provinces than across Chinese provinces.

Although these studies have systematically examined the drivers of household consumption volatility and proposed various channels for smoothing it, they lack a 
systematic assessment on household consumption volatility from the perspectives of heterogeneity in household consumption goods, cross-household differences, and intertemporal dynamics simultaneously. Doing so requires household survey data, but such studies have not been done. He et al. (2014) use aggregate consumption data at the province level in China from 1985 to 2011 and find that consumption risk sharing in China is limited, that is, China has high volatility of consumption. Ho et al. (2015) use a dataset of 24 Chinese provinces and 196 prefecture-level cities in those provinces from 1990 to 2010 and find that the ability to smooth consumption depends on initial economic development and the share of GDP contributed by tertiary industry.

In this article, we examine the contribution of the heterogeneity of consumption goods and short- and long-term volatility to household consumption and regional consumption patterns with two variance decomposition methods. The urban household survey (UHS) data on 18 provinces used in this article covers the period 2002-2009, collected by the National Bureau of Statistics (NBS) in China.

\section{Variance Decomposition Methods}

We initially use a traditional variance decomposition method proposed by Crucini (1999) to identify the impact of consumption of different goods on the variance in total consumption. Then, we apply an advanced variance decomposition method proposed by Crucini and Telmer (2012), to further study the relative importance of crosshousehold and intertemporal components on variance in total consumption. The traditional variance decomposition method is based on the variance formula and only 
relies on data. The model is not only simple and easy to operate, but also can accurately calculate the contribution rate of various commodities to the total consumption fluctuation. However, the shortcoming is that it cannot calculate the disparity in the cross-section and the variance fluctuation in the time series simultaneously. The advanced decomposition method can fill this gap, by calculating the above two aspects of a certain good at the same time. But compared with the traditional variance decomposition method, it is more complex, and cannot calculate the values of multiple commodities simultaneously. Therefore, this paper introduces both these two methods to study the contribution rate of different commodity consumption to the total consumption fluctuation, and to investigate the variance fluctuation of different commodities in the dimension of cross-section and time series.

In the traditional variance decomposition method, we denote $C_{t}$ as total consumption in year $t$ and $C_{i, t}(i=1,2, \ldots, j)$ as the consumption of good $i$ in year $t$. Thus, we have $C_{t}=C_{1, t}+C_{2, t}+\cdots+C_{j, t}$. Based on the definition of variance, we can obtain an expression of variance. The specific equation is:

$$
\operatorname{Var}\left(C_{t}\right)=\operatorname{Cov}\left(C_{t}, C_{t}\right)=\operatorname{Cov}\left[C_{t}, C_{1, t}+C_{2, t}+\ldots+C_{j, t}\right]=\operatorname{Cov}\left(C_{t}, C_{1, t}\right)+\ldots+\operatorname{Cov}\left(C_{t}, C_{j, t}\right)
$$

We revise equation (1) to obtain equation (2)

$$
1=\frac{\operatorname{Var}\left(C_{t}\right)}{\operatorname{Var}\left(C_{t}\right)}=\frac{\operatorname{Cov}\left(C_{t}, C_{1, t}\right)}{\operatorname{Var}\left(C_{t}\right)}+\ldots+\frac{\operatorname{Cov}\left(C_{t}, C_{j, t}\right)}{\operatorname{Var}\left(C_{t}\right)}=\beta_{1}+\ldots+\beta_{j}
$$

Here, we denote $\beta_{i}=\frac{\operatorname{Cov}\left(C_{t}, C_{i, t}\right)}{\operatorname{Var}\left(C_{t}\right)}, i=1,2, \ldots, j$ as the aggregate contribution of good $i$ to the variance in $C_{t}$. In this paper, we divide the total consumption of urban households into ten categories: food, wear, household equipment, health care, transportation, communication, education, recreation, housing, and other goods and 
services. Therefore, the value of $j$ is 10 .

Next, we use the advanced variance decomposition method proposed by Crucini and Telmer (2012) to examine whether household consumption volatility is due to cross-household differences or intertemporal dynamics. The specific equation is:

$$
\operatorname{Var}\left(c_{i j t} \mid i\right)=\operatorname{Var}_{j}\left(E_{t}\left(c_{i j t} \mid i, j\right)\right)+E_{j}\left(\operatorname{Var}_{t}\left(c_{i j t} \mid i, j\right)\right)
$$

where $c_{i j t}=\ln \left(C_{i j t}\right)-\ln \left(\overline{C_{i t}}\right)$. We collapse each category of consumption at the household level into the mean of a county. Then, we denote $C_{i j t}$ as the consumption of good $i$ in county $j$ in year $t$ and $\overline{C_{i t}}$ as total consumption of good $i$ in all counties in year $t$. Thus, we denote $c_{i j t}$ as the degree of deviation in the consumption of good $i$ in county $j$ in year $t$ compared to all counties. The conditional mean and variance operators, $E_{x}(\cdot \mid y)$ and $\operatorname{Var}_{x}(\cdot \mid y)$, denote the mean and variance calculated by integrating across the variables $x$ while conditioning on the variable $y$. $\operatorname{Var}_{j}\left(E_{t}\left(c_{i j t} \mid i, j\right)\right)$ is cross-household variance, across pairs of counties, in these intertemporal means. $E_{j}\left(\operatorname{Var}_{t}\left(c_{i j t} \mid i, j\right)\right)$ is the intertemporal mean of relative consumption for good $i$ between different counties. In this paper, we use the proportions of $\operatorname{Var}_{j}\left(E_{t}\left(c_{i j t} \mid i, j\right)\right) / \operatorname{Var}\left(c_{i j t} \mid i\right)$ and $E_{j}\left(\operatorname{Var}_{t}\left(c_{i j t} \mid i, j\right)\right) / \operatorname{Var}\left(c_{i j t} \mid i\right)$ to reflect the impacts of cross-household components and intertemporal components on total variance.

\section{Data Description and Stylized Facts}

\subsection{Data Description}

The main analysis relies on data from the urban household survey (UHS) conducted by NBS of China, using a probabilistic sampling and stratified multistage method. It is a rotating panel in which one-third of the sample is replaced before 2007, 
and the full sample is changed every three years. Beginning in 2007, half the sample in the rotating panel is replaced, and the full sample is changed every two years. Therefore, the data are essentially repeated cross-sectional data ( $\mathrm{Li}$ et al., 2016). The survey collects demographic and detailed information on household consumption (including the quantity of each item). We have access to data gathered in 18 provinces in China from 2002 to 2009. Our data are the most appropriate among the data that are accessible because of their detailed classification of consumption goods. For example, household expenditures in the UHS are the total expenditures on 180 types of goods and servers.

Based on the degree and phase of economic development, China could be divided into four subregions: eastern region, central region, western region, and northeastern region. In our sample, the eastern region consists of only six provinces (or the equivalent): Beijing, Shanghai, Jiangsu, Zhejiang, Shandong, and Guangdong; the central region consists of five provinces: Shanxi, Anhui, Jiangxi, Henan, and Hubei; the western region consists of five provinces: Chongqing, Sichuan, Yunnan, Shaanxi, and Gansu; and the northeastern region consists of two provinces: Liaoning and Heilongjiang.

Unlike the previous literature, which divides consumption into three categoriesdurable goods, nondurable goods, and services - we divide the total consumption of urban households into ten categories: food, wear, household equipment, health care, transportation, communication, education, recreation, housing, and other goods and services. The three-category classification can only analyze the contribution rate of the three commodity consumption bundles to the fluctuations of total household 
consumption. In the UHS data, household expenditures are the total expenditures on 180 types of goods and the servers. However, it is not necessary to study the fluctuations of total household consumption according to 180 classifications. In view of this, this paper adopts the ten-category classification to make an empirical study considering the characteristics of Chinese household consumption. This detailed classification enables us to examine the impact heterogeneous consumption goods on urban household consumption volatility in China, measured by the variance.

To calculate the real consumption per capita of urban households, we first divide each household consumption expenditure by the total number of family members. The nominal consumption per capita is converted into real values using the fixed-base consumer price index, which is 100 in 2002, at each prefecture-level city obtained from the NBS in terms of RMB per capita. Table 1 presents the statistics on all the variables.

Table 1. Summary statistics of real consumption per capita, total and by category, RMB per capita $(N=306,606)$

\begin{tabular}{|c|c|c|c|c|c|}
\hline Variables & Label & Mean & $\begin{array}{l}\text { Standard } \\
\text { deviation }\end{array}$ & Min. & Max. \\
\hline Total consumption & Total-C & 8532 & 7908 & 280 & 680500 \\
\hline Food consumption & Food & 3160 & 2090 & 111 & 140251 \\
\hline Wear consumption & Wear & 873 & 991 & 0 & 143028 \\
\hline $\begin{array}{c}\text { Consumption of household } \\
\text { equipment }\end{array}$ & Equipment & 518 & 1251 & 0 & 210332 \\
\hline Health care consumption & Health & 660 & 1547 & 0 & 104312 \\
\hline Transportation consumption & Transportation & 559 & 3386 & 0 & 342181 \\
\hline $\begin{array}{l}\text { Communication } \\
\text { consumption }\end{array}$ & Communication & 491 & 506 & 0 & 12869 \\
\hline Recreation consumption & Recreation & 580 & 1284 & 0 & 200547 \\
\hline Education consumption & Education & 534 & 1174 & 0 & 114008 \\
\hline Housing consumption & Housing & 847 & 2250 & 0 & 280111 \\
\hline $\begin{array}{l}\text { Consumption of other } \\
\text { goods and services }\end{array}$ & Others & 310 & 766 & 0 & 83169 \\
\hline $\begin{array}{c}\text { Total consumption in the } \\
\text { Eastern region }\end{array}$ & $T C E$ & 10633 & 10173 & 292 & 680499 \\
\hline
\end{tabular}




\begin{tabular}{|c|c|c|c|c|c|}
\hline $\begin{array}{l}\text { Total consumption in the } \\
\text { Central region }\end{array}$ & $T C C$ & 6747 & 4761 & 545 & 120279 \\
\hline $\begin{array}{c}\text { Total consumption in the } \\
\text { Western region }\end{array}$ & $T C W$ & 7214 & 5483 & 280 & 234356 \\
\hline $\begin{array}{l}\text { Total consumption in the } \\
\text { Northeastern region }\end{array}$ & $T C N$ & 7068 & 5326 & 625 & 127352 \\
\hline
\end{tabular}

The total sample of Chinese urban households surveyed from 2002 to 2009 exceeded 300,000. During this period, the average of real total consumption per capita of urban households is RMB 8,532, and daily necessities such as food and wear are the largest categories of consumption. Average real food consumption per capita is RMB 3,160 , making up $37 \%$ of the real total consumption per capita. Ranking second and third are real wear consumption per capita (RMB 873) and real household equipment consumption per capita (RMB 847). The average in the seven other categories of consumption is less than RMB 800 per capita. By region, average real total consumption per capita in the eastern region, RMB 10633, is higher than the national average and the other three regions. By contrast, average real total consumption per capita in the central region is the lowest among the four regions.

According to the standard deviation and the gap between the maximum and minimum values, real total consumption per capita fluctuates significantly, which indicates that the level varies significantly across households. Among the ten consumption categories, transportation is the most volatile, followed by housing and food, and communication and wear are the least volatile.

\subsection{Stylized Facts of Total Consumption and Income}

We collapse the variable of real total consumption per capita at the household level into the mean for the year. We have eight year generated from 306,606 observations at 
the household level. The level and growth rate of household consumption per capita shows significant difference across the four regions. The growth of real total consumption per capita of urban households in the northeastern region is faster than the national average, while that of the other three regions is lower than the national average. The northeastern region has the highest increase in total consumption of urban households, nearly $400 \%$. The eastern region has the second highest increase (320\%). The western region has the third highest (278\%) and the central region is in last place (268\%). The level of consumption in the eastern region is higher than the national average, whereas in the other three regions it is lower than the national average.

The volatility level of total consumption per capita in China also has clear regional heterogeneity, that is, urban households in the eastern region have relatively high consumption volatility, while those in the other three regions have relatively low consumption volatility. Figure 1 shows the volatility trend in total consumption per capita of urban households in 18 provinces from 2002 to 2009, indicating an increase year by year of more than $360 \%$ over the period. The volatility level of total consumption per capita is much higher in the eastern region than in the western and northeastern regions; total consumption per capita in the central region fluctuates the least among the four regions. This result suggests that an analysis of regional heterogeneity may offer significant insights into the true causes of household consumption volatility in China. 


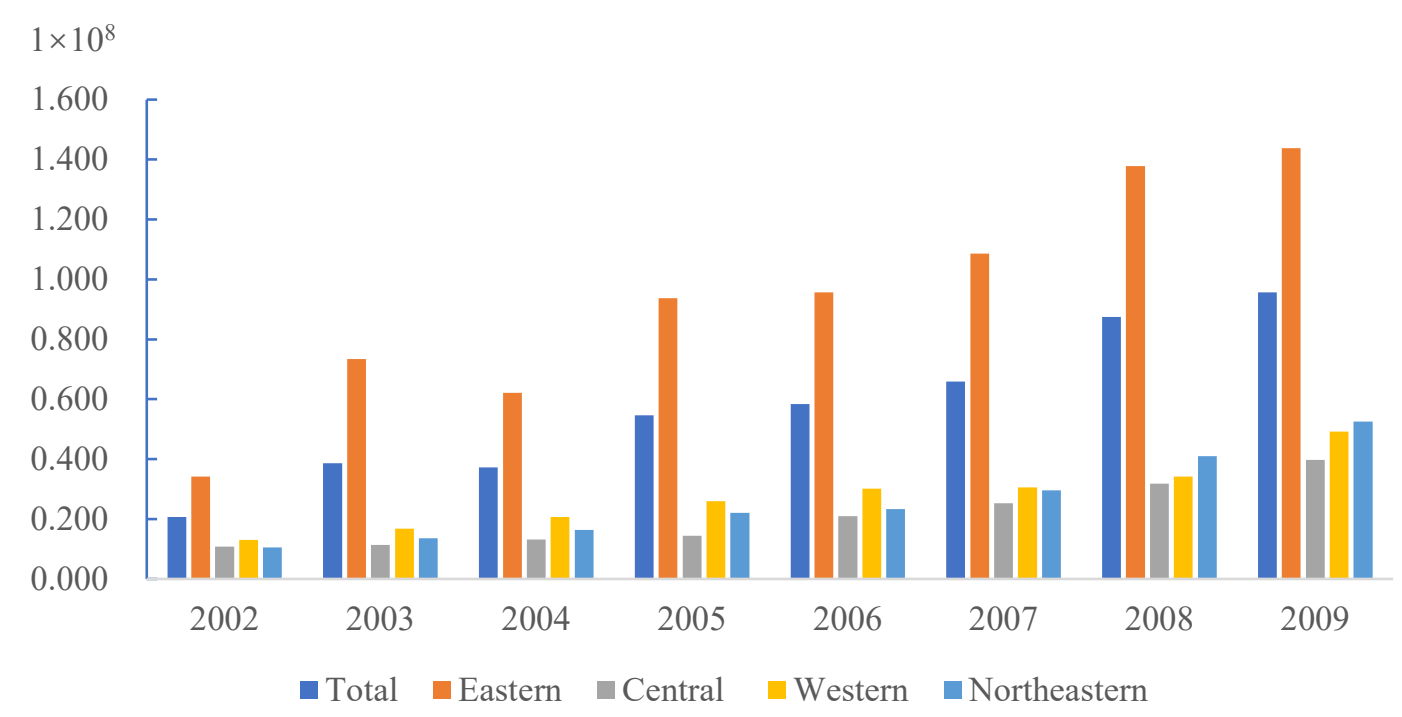

Figure 1. Variance in real total consumption per capita by China's urban

\section{households, 2002 to 2009}

Because income is a key factor that influences consumption volatility, we also examine income disparity across regions. Figure 2 shows the fluctuation in real total income per capita of urban households in different regions from 2002 to 2009, indicating an annual increase of more than $100 \%$ over the period, from RMB 8,185 in 2002 to RMB 16,506 in 2009. Incomes of urban households are much higher in the eastern region than in other regions, increasing more than 95\%, from RMB 10,514 in 2002 to RMB 20,587 in 2009, followed by the central and western regions; incomes in the northeastern region are the lowest among the four regions. 


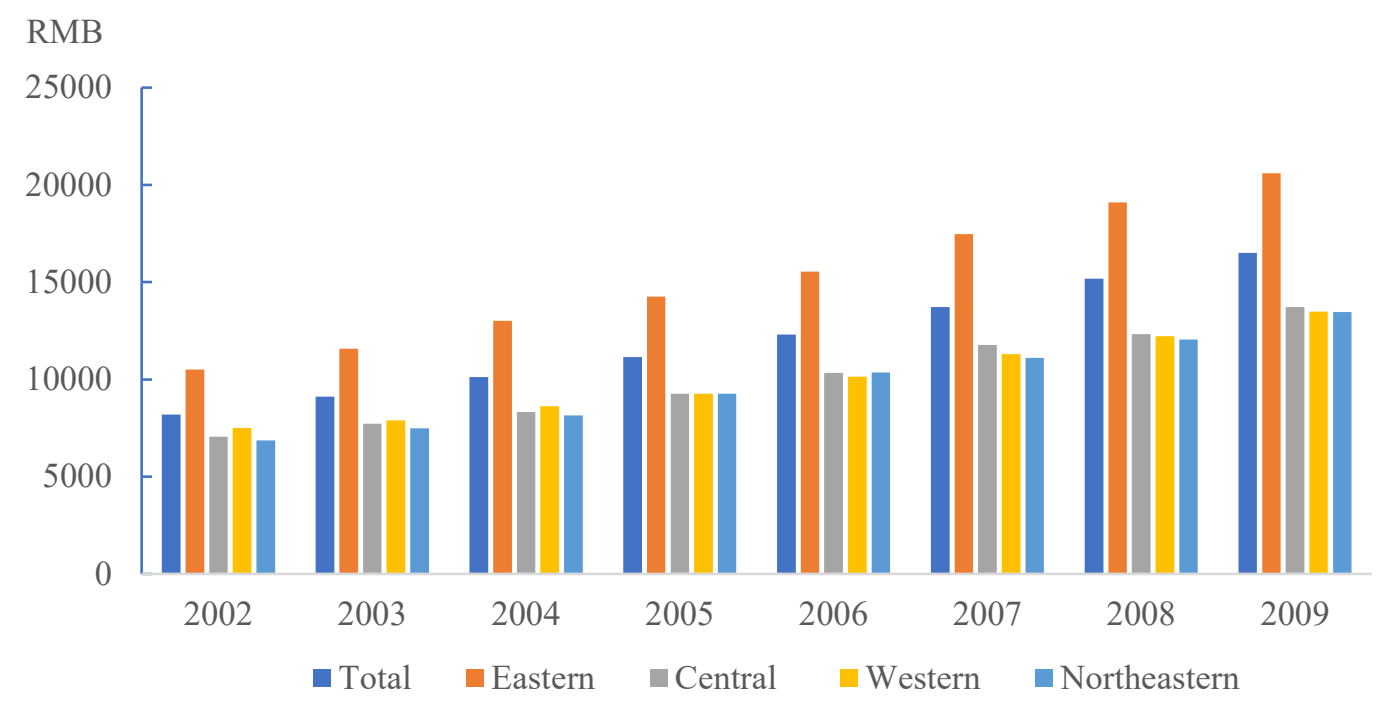

Figure 2. Real total income per capita for China's urban households, 2002 to 2009

\section{Empirical Results}

\subsection{Traditional variance decomposition: aggregate contribution and per-unit} volatility

The aggregate contribution of various categories of consumption goods to total consumption volatility in Chinese urban households could be influenced by two factors: the share of each category of consumption goods in total consumption and the volatility level of each category. To separate the impact of the share of consumption shares - that is, a scale effect-we introduce per-unit volatility to reflect the contribution of each category of consumption goods to total consumption volatility (per-unit contribution). Per-unit volatility is equal to the aggregate contribution of each good divided by the share of various categories of consumption goods. Consumption with high per-unit volatility could cause high total household consumption volatility even though its share of total consumption may not be significant. The other factor is this category of 
consumption goods as a share of total consumption. Consumption with low per-unit volatility could still have a significant impact on total household volatility if its share is large. The combined effect of per-unit volatility and share on total consumption volatility is called the aggregate contribution. Determining per-unit volatility indicates where policy can be imposed.

As shown in Figure 3, the average share of each category of consumption goods from 2002 to 2009 has significant variation. Among the ten categories, food has the highest share, accounting for $42.59 \%$ on average over the period. Wear has the secondlargest share (10.67\%), and housing has the third-largest share $(9.74 \%)$. By contrast, the share of transportation is only $3.93 \%$.

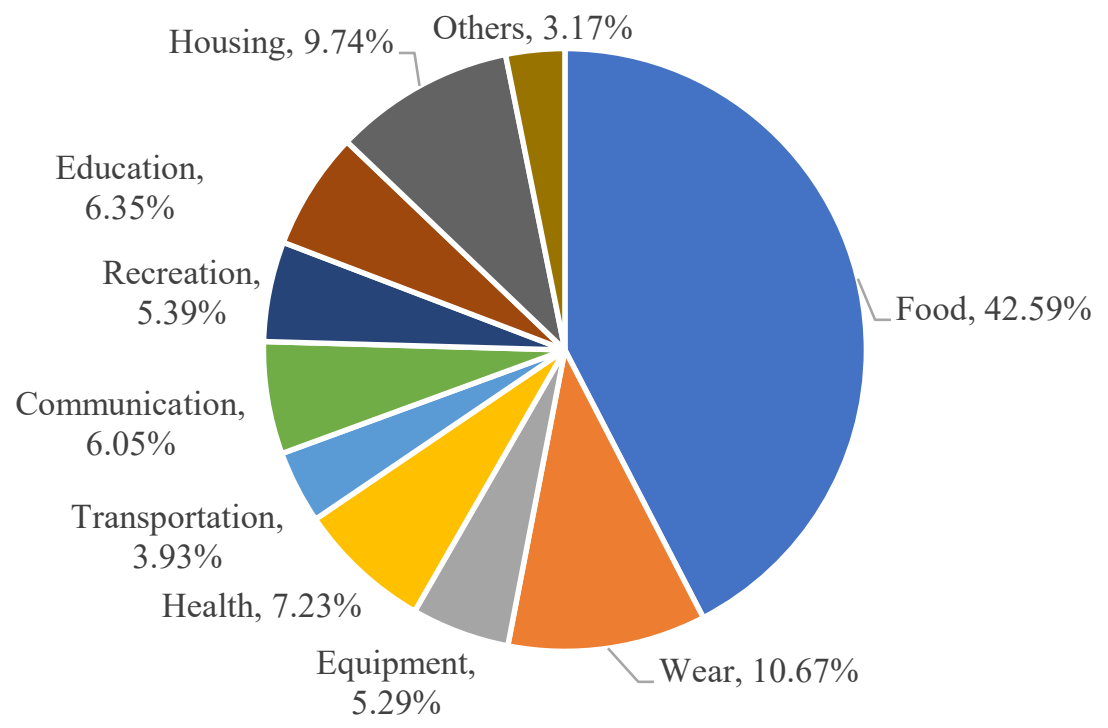

Figure 3. The average share of each category of consumption goods from 2002 to 2009

\subsubsection{Aggregate contribution}

Figure 4 shows the decomposition result of the aggregate contribution of each category of consumption goods in total consumption volatility. The aggregate 
contribution of the key drivers has significant variation over time. The largest factor, transportation, has the smallest aggregate contribution in $2003(12.56 \%)$ and the largest aggregate contribution in 2005 (38.18\%). The second-largest factor is food, which has the smallest aggregate contribution in $2005(14.18 \%)$ and largest aggregate contribution in $2002(19.52 \%)$. Housing, the third-largest factor, has the smallest aggregate contribution in 2005 (9.64\%) and the largest aggregate contribution in 2003 (30.77\%).

On average, more than half (57\%) of urban households' consumption volatility is caused by transportation, food, and housing. Transportation is the primary driver of total consumption volatility in the 18 provinces examined here, comprising about onefourth on average over the sample period. The dominance of transportation in total consumption can be explained by the components of transportation consumption. In the UHS definition, transportation consumption consists of the cost to purchase private vehicles, fuel and parts expenditure, service and maintenance costs, and public transportation expenditure, including both local and long-distance transportation costs. Because private vehicles often incur a large transaction cost one in many years, their purchase creates significant volatility for a household. Furthermore, with increasing income, households demand more and more advanced public transportation, such as air travel, which has a significant cost difference from normal urban transportation.

Food is the second-largest driver, contributing $17.46 \%$ to total consumption volatility. Although food is a necessity and thus has little volatility, its large share of consumption amplifies volatility. Housing is the third-largest driver, contributing $14.13 \%$ of total consumption volatility. Housing consumption volatility is due to the rising price 
of property and rent, as well as increasing electricity and gas consumption due to income growth.

The aggregate contribution of the other seven categories to total consumption volatility is less than 10\%: recreation, 9.05\%; household equipment, $8.73 \%$; wear, $6.83 \%$; and health care, $6.51 \%$. The aggregate contribution of communication, education, and other goods and services is less than $5 \%$.

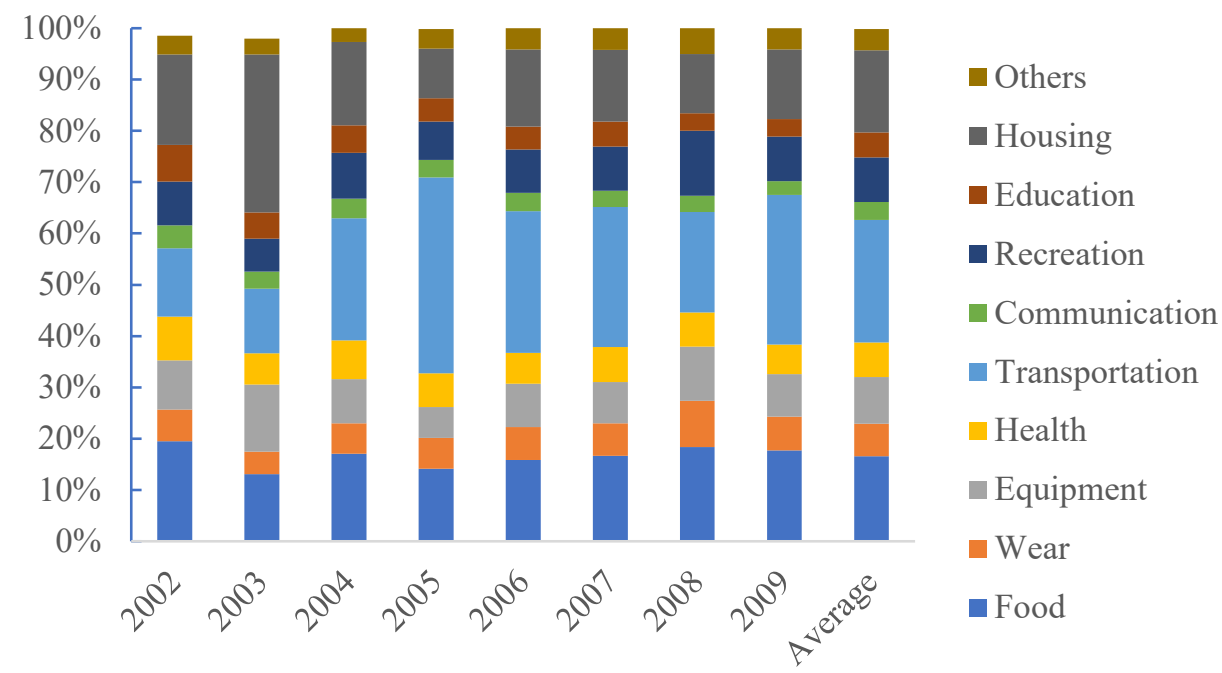

Figure 4. Decomposition of total consumption variance by category of consumption goods

\subsubsection{Per-unit volatility}

To remove the influence brought by the consumption proportion of a certain commodity and truly reflect the contribution rate of each commodity to total consumption volatility, we introduce the per-unit volatility into this paper. Figure 5 illustrates the per-unit volatility of each category of consumption goods: transportation has a high per-unit volatility, from a low of 3.84 in 2003 to a high of 10.15 in 2005 . From 2002 to 2009 , the average per-unit volatility of transportation is 6.14 . This result 
shows that the high aggregate contribution of transportation mainly comes from the high per-unit volatility. If the share of transportation consumption remains unchanged, when transportation consumption increases by $1 \%$, total consumption of urban households rises by $6.14 \%$.

In comparison, the per-unit volatility of food is the lowest among all the categories. Its per-unit volatility went from a low of 0.31 in 2003 to a high of 0.46 in 2002 . On average, from 2002 to 2009 the per-unit volatility of food is only 0.39 . This result shows that the high aggregate contribution of food to total consumption volatility comes mainly from its high share of total household consumption (42.59\%, in Figure 3). When the share of food is held constant, if food consumption rises by $1 \%$, total consumption volatility increases by only $0.39 \%$. In addition to the consumption of transportation, the per-unit volatility of household equipment, recreation, housing, and other goods and services is between 1.4 and 1.7 on average, whereas the per-unit volatility of wear, health care, communication, and education is between 0.45 and 0.9 on average.

According to this dynamic analysis, total household consumption volatility increases over time, which is bad news for Chinese economic policy makers who want to stabilize economic growth. This is because with income growth and consumption increases, more volatile transportation expenditure makes up a larger share of total consumption of urban households and leads to a smaller share of less volatile expenditures on food and clothes. In order to improve people's quality of life, to accelerate the upgrading of consumption and to more closely control the fluctuation of consumption, the government should encourage people to increase their consumption 
of culture, tourism, education and entertainment services. Even if the government strongly encourages people to buy more vehicles, it must introduce the payment by instalments, which could effectively reduce the fluctuation of consumption.

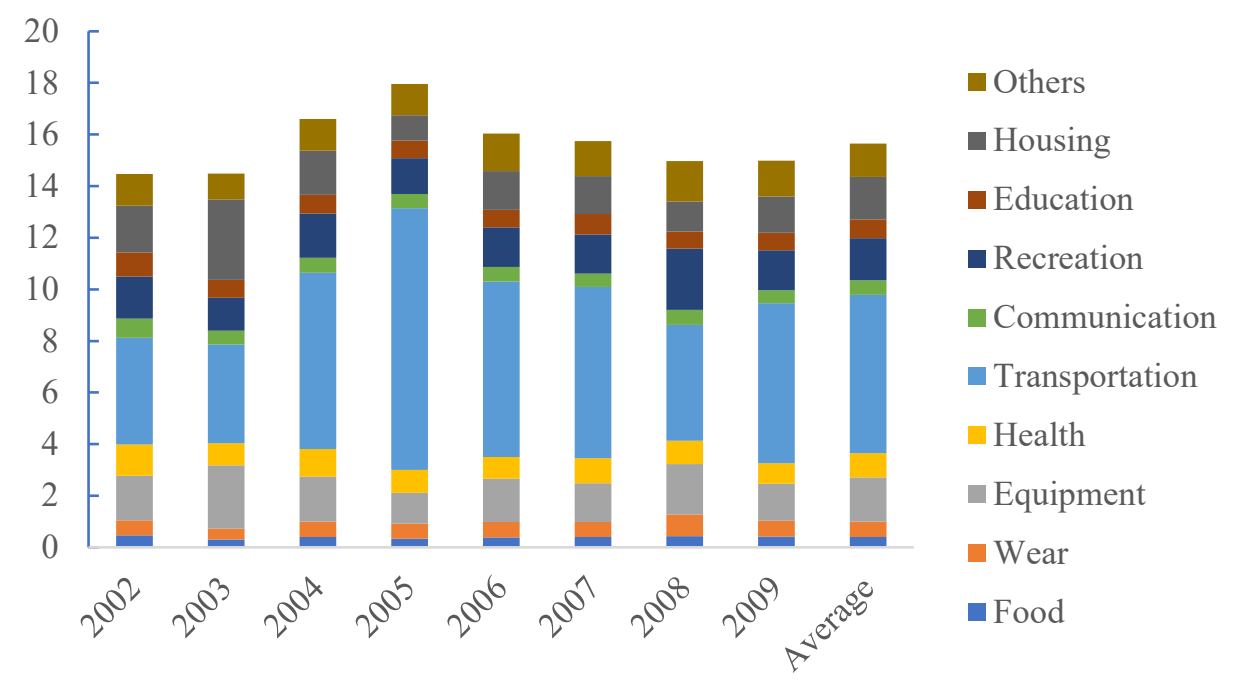

Figure 5. The per-unit volatility of each category of consumption goods

\subsection{Advanced variance decomposition: cross-household differences and} intertemporal dynamics

Following Crucini and Telmer (2012), we decompose the total variance of real consumption per capita into two parts: cross-household differences and intertemporal dynamics. The cross-household differences reflect the deviation in the regional (county) average household consumption per capita to the national average. The larger the value of cross-household differences is, the greater the difference in deviation between the regional urban household consumption level and the national average, which reflects disparity in consumption levels across China's regions. The intertemporal dynamics are a short-term nonstructural difference caused by the business cycle, which describes the difference in the deviation in individual household consumption relative to the national 
average in different years. The larger the value of intertemporal dynamics, the greater the dynamic difference in the time dimension of the degree of deviation in the consumption level from the national average. If cross-household differences divided by intertemporal dynamics are more than one, then regional imbalance (disparity) is the main force in the volatility of urban household consumption. On the contrary, if the result is less than one, then the short-term dynamic change caused by the business cycle is the main cause of volatility in urban household consumption.

Figure 6 illustrates the results of variance decomposition of different consumption goods in Chinese urban households. First, the total volatility $\left(0.405 \times 10^{8}\right)$ of total consumption of urban households during 2002 and 2009 can be attributed to crosshousehold differences of $0.111 \times 10^{8}$ and intertemporal dynamics of $0.294 \times 10^{8}$. The ratio of cross-household differences divided by the variance of intertemporal dynamics is 0.38 , which shows that the short-term dynamic change caused by the business cycle plays a more important role in determining the volatility of urban household consumption in China than structural factors caused by cross-household differences.

Second, from the perspective of heterogeneity of consumption goods, the consumption of daily necessities, mainly food, wear, and housing, lacks volatility, which is consistent with their low per-unit volatility (in section 5.1.2), and the volatility of urban household consumption has obvious heterogeneity of consumption goods. Among the ten categories of consumption goods, education, recreation, transportation, and health care have large variance, whereas food, wear, and housing have less variance. This is because food, wear, and housing consumption have low-income elasticity 
whereas recreation, transportation, health care has high-income elasticity. Hence, an increase in family income and associated consumption upgrades inevitably cause great volatility in recreation, transportation, and health care consumption. Further analysis shows that, for any good, the ratio of cross-household differences to intertemporal dynamics is significantly less than one.

Both the regional and goods perspective results show that the main determinant of the volatility of different consumption goods of urban households in China is intertemporal dynamics caused by the business cycle, rather than structural differences caused by cross-household differences.

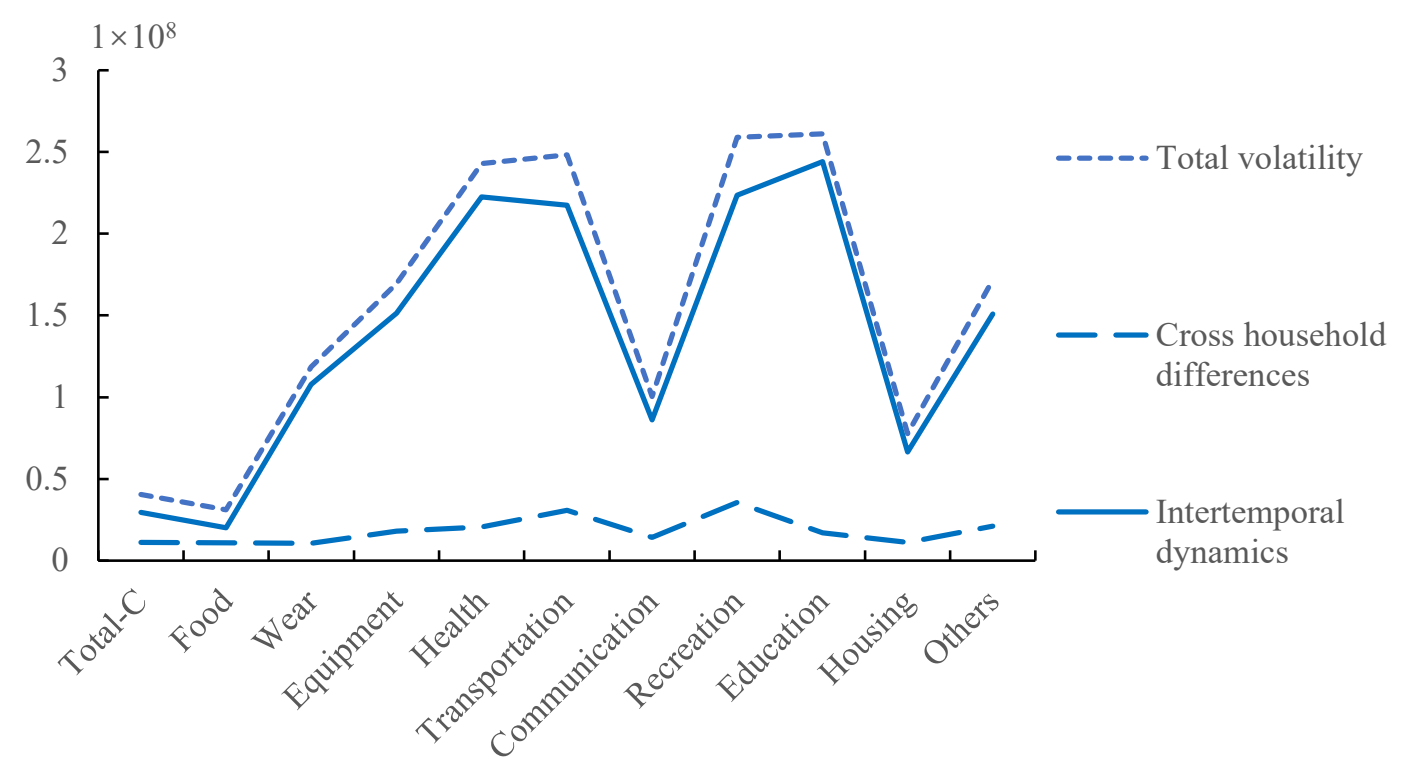

Figure 6. Advanced variance decomposition of different consumption goods in

China's urban households from 2002 to 2009

\subsection{Geographic differences}

In this section, we introduce cross-sectional heterogeneity within a single economy based on differences related to economic geography. Figure 7 shows the volatility of total consumption and each category of consumption goods in different 
regions of China. The volatility on real per capita consumption of urban households has significant characteristics of dynamic change and regional imbalance. From 2002 to 2009, the variance in real total consumption per urban household is much larger in the eastern region than in the central, western, and northeastern regions. Volatility in total household consumption is significantly larger in eastern China than in the other three regions, which is also shown in Figure 1.

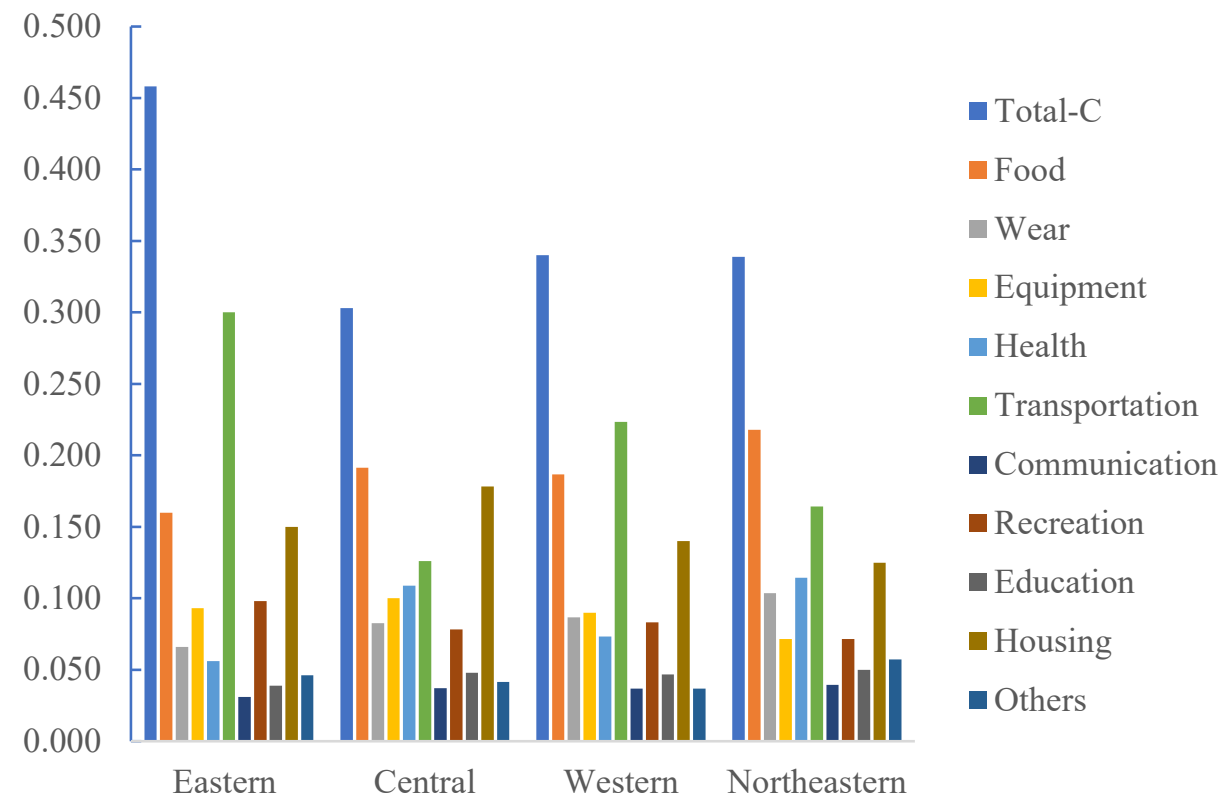

Figure 7. Volatility of total consumption and each category of consumption goods, by region

Furthermore, Figure 8 reports the regional differences in the volatility of total consumption and by each type of consumption, because our primary interest here is examining the contribution of each type of consumption good to total consumption volatility. The figure shows that consumption volatility in transportation is greater among urban households in eastern China than in the central, western, and northeastern 
regions. By contrast, consumption volatility in food and wear is lower in eastern China than in the other three regions, whereas consumption volatility for other goods shows no significant difference across different regions. This result shows that regional disparity lead directly to high consumption volatility of transportation, food, and wear by urban households in different regions.

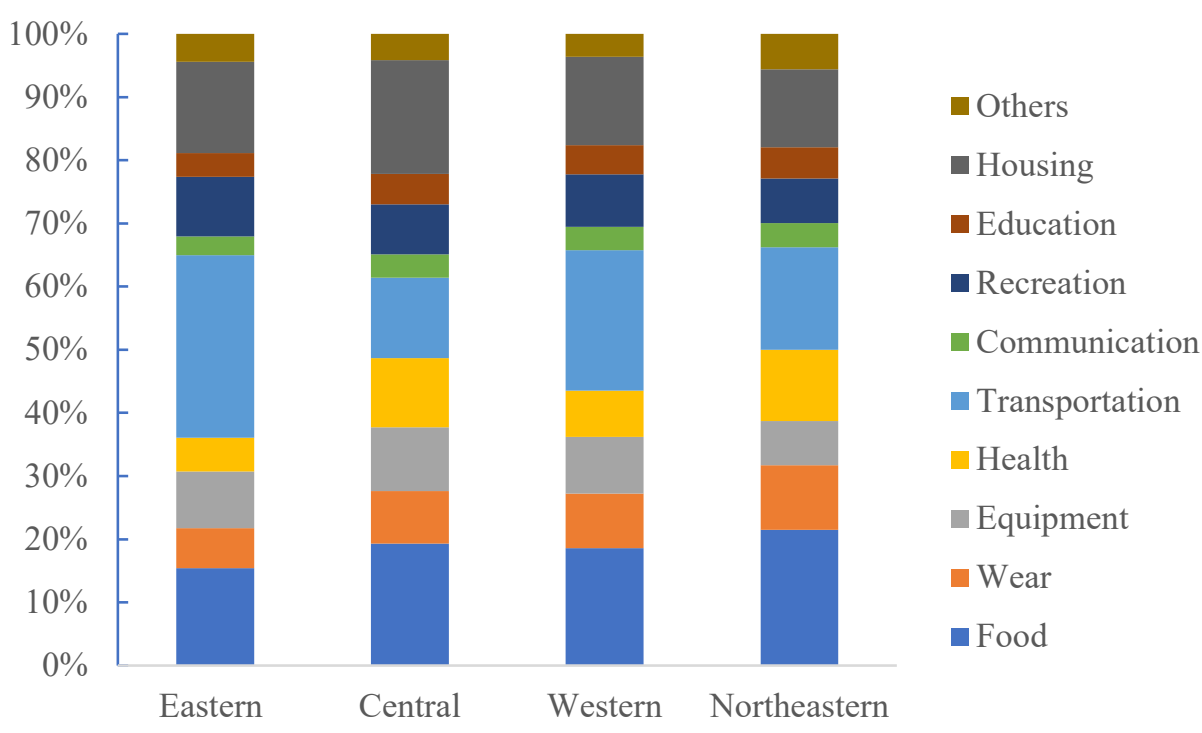

Figure 8. The aggregate contribution of each category of consumption goods, by region

Figure 9 illustrates the proportion of intertemporal dynamics in total volatility in different regions. First, we can see that the variance in intertemporal dynamics is higher than $55 \%$ in both the volatility of total consumption and the consumption volatility of different goods. The results show that intertemporal dynamics caused by the business cycle are the main cause of volatility in total consumption and consumption of different goods in different regions of China, while cross-household differences are only the 
secondary reason.

Second, the variance ratio of intertemporal dynamics is much smaller in the eastern region than in the other three regions in terms of the volatility of total consumption and different goods consumption. This result shows that in different counties in eastern China, the cross-household differences have a great impact on the volatility of urban household consumption. This further indicates that the higher the household income level is between different regions, the more influence the cross-household differences have on total consumption volatility.

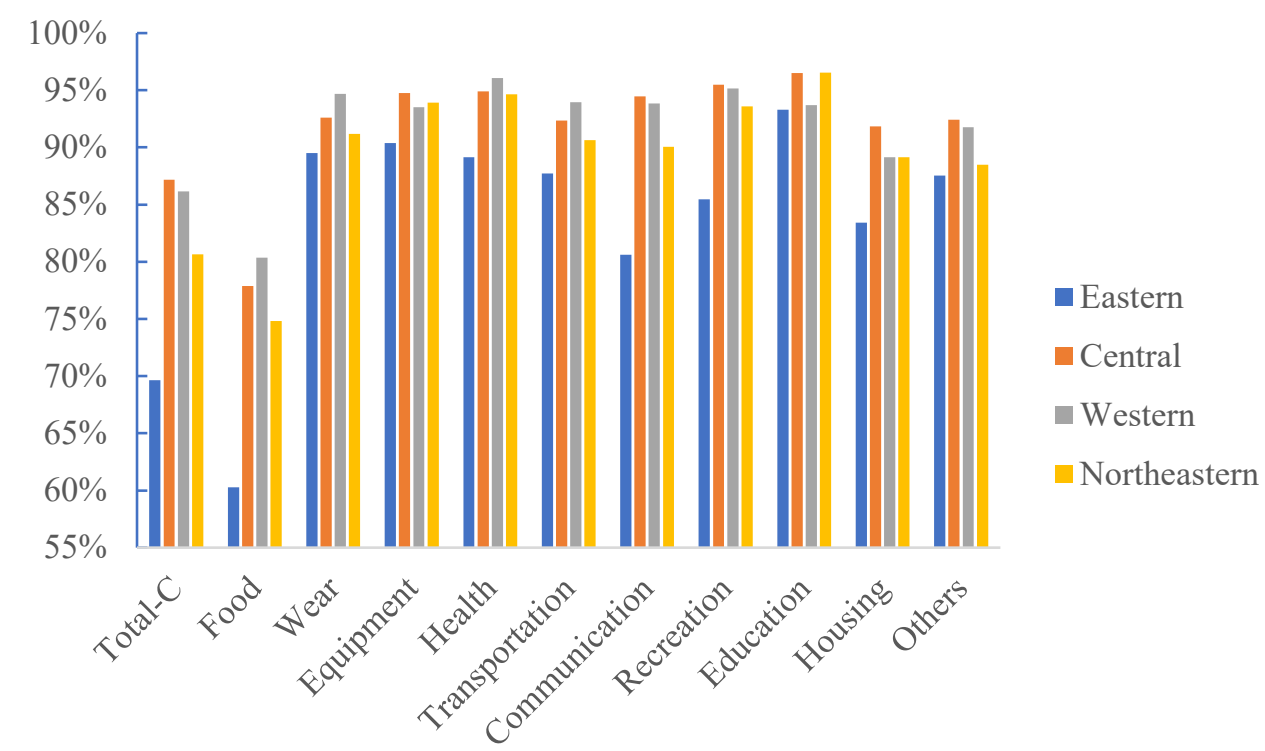

Figure 9. The proportion of intertemporal dynamics in total volatility, by region

\subsection{Comparison with international standard decomposition}

Following the general practice in the literature, and in order to facilitate international comparisons, we divide the total consumption of urban households into durables, nondurables, and services in accordance with international classification 
standards (BEA, 2014). Durables goods, nondurable goods, services expenditures in the UHS are the total expenditures on 66, 63 and 51 types of goods respectively. We find that, from 2002 to 2009 , the average aggregate contribution of durable goods to total consumption of urban households is $46.03 \%$, much larger than that of nondurable goods $(20.63 \%)$ and services $(33.33 \%)$. This result indicates that durable goods and services are responsible for consumption volatility among the urban households in 18 Chinese provinces.

Even after eliminating the share of consumption of durables, nondurables, and services, the per-unit volatility of durable goods to total consumption of urban households is still much larger than that of the other two kinds of goods. Among them, the per-unit volatility of durables is 3.73 , which means that holding the consumption share of various goods constant, when the expenditure of durable goods changes by $1 \%$, the total consumption of urban households changes by $3.73 \%$. The per-unit volatility of services and nondurables is 0.88 and 0.42 respectively. By contrast, the per-unit volatility of nondurables is less than $12 \%$ that of durable goods.

In summary, durables have high aggregate contribution and high per-unit volatility, while nondurables have low aggregate contribution and low per-unit volatility, and the services are in between. This finding is consistent with Cecchetti et al. (2006), and Zhao and Hsu (2012). They argue that in developed countries durable goods are frequently cited as an important factor driving consumption volatility. Therefore, consumption of durables is worth particular attention because expenditures on durable goods are highly volatile, and the dynamics of spending on durables differ significantly from that of 
spending on nondurables. This finding suggests that smoothing the consumption of durable goods and services by urban households is the key to reducing the volatility of total consumption of China's urban households. However, the three-goods classification method that is usually adopted in literatures to study the household consumption volatility lacks sufficient heterogeneity of consumption goods compared with the ten-good classification proposed in this paper, and thus the previous studies cannot truly reveal the fundamental of household consumption volatility.

\section{Conclusion}

Consumption is the key component in economic growth, and volatility in consumption is an important subject in economic studies. Household consumption volatility is particularly important in China, which is in the midst of changing its growth model, lowering its growth rate, upgrading consumption, and facing trade frictions. However, the existing studies on Chinese household consumption mainly use national or provincial aggregate data and thus underestimate the volatility of household consumption. Although these papers have systematically examined the drivers of household consumption volatility and proposed various channels for smoothing it, they lack a systematic assessment of household consumption volatility from the perspectives of heterogeneity in household consumption goods, regional disparity, and intertemporal dynamics simultaneously. To design a sensible and effective economic policy, Chinese policy makers need a better understanding of the determinants of consumption volatility.

Unlike those existing studies, this paper assesses household consumption volatility 
from those perspectives with both a traditional variance decomposition method and an advanced variance decomposition method using a sample of urban household survey data during 2002-2009 — the only available data with details on consumption goods. Our contribution consists of analyzing the contributions of heterogeneity in household consumption goods on consumption volatility and demonstrating short-term (intertemporal dynamic) and long-term (cross household) volatility. This decomposition methodology allows us to examine where household consumption volatility is due to cross-household or intertemporal dynamics, which is needed for appropriate policy interventions.

Traditional variance decomposition suggests that heterogeneity of consumption goods is the key to analyzing consumption volatility in China. Consumption of transportation makes the largest aggregate contribution to consumption volatility and has the largest per-unit volatility in 18 provinces in China, whereas consumption of food makes the second-largest aggregate contribution and the smallest per-unit volatility. Further investigation using the advanced variance decomposition method reveals that the main factor determining consumption volatility in China is intertemporal dynamics caused by the business cycle, rather than cross-household differences. Furthermore, our analysis demonstrates that heterogeneity in consumption goods is an important factor in the volatility of total consumption by Chinese urban households. If the heterogeneity of consumption goods is not taken into account, we might miss the fundamental cause of volatility in total consumption by urban households. 
Our findings have the following implications. First, our results show that in order to reduce total consumption volatility in China's urban households, policy should focus on maintaining smooth urban household consumption of transportation and food.

Second, considering transportation consumption is the primary driver of total consumption volatility in the 18 provinces of China and is carbon intensive, we suggest that governments, mainly city governments, need to provide affordable and reliable public transportation and facilitate consumers to low carbon consumption choices, which is an important factor to reduce emissions ( $\mathrm{Li}$ et al, 2019). The promotion of public transit can generate double benefits: on the one hand, it can reduce the volatility of transportation consumption, by discouraging the purchase of private vehicles; on the other hand, it can reduce energy consumption and emissions and thus contribute to sustainable development.

Third, the impact of an increasing consumption upgrading on consumption volatility should be taken into account so that to minimize the consumption volatility from consumption upgrading. Continuous economic development will drive consumption upgrades that include changing the structure of food consumption- - for example, increasing the share of beef over that of vegetables, and the consumption of beef has greater volatility. The move toward consumption goods with more volatility requires policy responses. For example, further development of consumer credit services is desirable. Installment payments, often in equal amounts, smooth consumption over time and thus greatly reduce per-unit volatility and then aggregate volatility. Expenditures can be financed for durable goods, large purchases, and those 
for which only one is purchased per household, such as private vehicles_-all of which are relevant for transportation, the largest contributor to volatility in consumption.

Fourth, although cross-household differences play a less important role than intertemporal dynamics in determining total consumption volatility, the amount of those differences is significant, so policy makers need to pay attention to crosshousehold disparity and heterogeneity in consumption goods.

Last, smoothing consumption volatility requires regionally specific policy. Given the differences among goods that are the primary contributors to total consumption variability across regions, policies intended to smooth consumption volatility need to take regional heterogeneity of consumption goods into account.

Future research could fruitfully explore two issues. First, consumption upgrading has increased the volatility of China's household consumption. How much will this affect economic growth in China under its "new normal" conditions, and how should the Chinese government respond? Second, differences between UHS data and aggregate data in the calculations of consumption risk sharing need to be investigated. Third, is important to investigate the channels through which the Chinese government can enhance its ability to spread consumption risks and thus reduce consumer consumption volatility. Lastly, further study could extend the current 18 provinces to a national wide sample and update the data beyond 2009 to estimate the impact of the global financial crisis. 


\section{References}

Ambrus, A., Mobius, M. and Szeidl, A. (2014). "Consumption risk-sharing in social networks", American Economic Review, Vol.104 No.1, pp.149-182.

Amendola, A., Candila, V. and Gallo, G. M. (2019). "On the asymmetric impact of macrovariables on volatility", Economic Modelling, Vol.76 No.1, pp.135-152.

Ansar, A., Flyvbjerg, B., Budzier, A. and Lunn, D. (2016). "Does infrastructure investment lead to economic growth or economic fragility? Evidence from China", Oxford Review of Economic Policy, Vol.32 No.3, pp.360-390.

Ang, J. B. (2011). "Finance and consumption volatility: Evidence from india", Journal of International Money and Finance, Vol.30 No.6, pp.947-964.

Asdrubali, P., Sørensen, B. E. and Yosha, O. (2006). "Channels of interstate risk sharing: United States 1963-1990”, Quarterly Journal of Economics, Vol.111 No.4, pp.1081-1110.

Athanasoulis, S. G. and Van Wincoop, E. (2001). "Risk sharing within the united states: What do financial markets and fiscal federalism accomplish?" Review of Economics and Statistics, Vol.83 No.4, pp.688-698.

Boileau, M. and Normandin, M. (2017). "The price of imported capital and consumption fluctuations in emerging economies", Journal of International Economics, Vol.108, pp.67-81.

Bosworth, B. and Collins, S. M. (2008). "Accounting for growth: Comparing China and India", Journal of Economic Perspectives, Vol.22 No.1, pp.45-66.

Bureau of Economic Analysis (BEA), U.S. Department of Commerce. (2014). "Concepts and methods of the U.S. national income and product accounts", https://www.bea.gov/resources/methodologies/nipa-handbook/.

Buckley, P. (2019). "China goes global: provenance, projection, performance and policy", International Journal of Emerging Markets, Vol.14 No.1, pp.6-23.

Cecchetti, S. G., Flores-lagunes, A. and Krause, S. (2006). "Assessing the Sources of Changes in the Volatility of Real Growth", NBER Working paper No.11946.

Chan, K. S., Lai, J. T. and Yan, I. K. M. (2014). "Consumption risk sharing and self-insurance across provinces in China: 1952-2008", China Economic Review, Vol.30, pp.66-85.

Chen A. Y. (2017). "External habit in a production economy: A model of asset prices and consumption volatility risk", Review of Financial Studies, Vol.30 No.8, pp.2890-2932.

Chen A. and Groenewold, N. (2018). "China's 'New Normal': Is the growth slowdown demand- or supply-driven?", China Economic Review, https://doi.org/10.1016/j.chieco.2018.07.009.

Chen, J., Guo, F. and Zhu, A. (2009). "Housing wealth, financial wealth and consumption in China", China and World Economy,Vol.17 No.3, pp.57-74.

Crucini, M. J. (1999). "On international and national dimensions of risk sharing", Review of Economics and Statistics, Vol.81 No.1, pp.73-84.

Crucini, M. J. and Telmer, C. I. (2012). "Microeconomic sources of real exchange rate variability”, NBER Working paper No.17978.

De Giorgi, G. and Gambetti, L. (2017). "Business cycle fluctuations and the distribution of consumption", Review of Economic Dynamics, Vol.23, pp.19-41.

Dogra, K. and Gorbachev, O. (2016). "Consumption volatility, liquidity constraints and household welfare", Economic Journal, Vol.126 No.597, pp.2012-2037. 
Du, J., He, Q. and Rui, O. M. (2010). "Does financial deepening promote risk sharing in China?", Journal of the Asia Pacific Economy, Vol.15 No.4, pp.369-387.

Du, J., He, Q. and Rui, O. M. (2011). "Channels of interprovincial risk sharing in China", Journal of Comparative Economics, Vol.39 No.3, pp.383-405.

Eusepi, S. and Preston, B. (2015). "Consumption heterogeneity, employment dynamics and macroeconomic co-movement", Journal of Monetary Economics, Vol.71, pp.13-32.

Guo, F. and Huang, Y. (2010). "Hot money and business cycle volatility: Evidence from China", China and World Economy, Vol.18 No.6, pp.73-89.

Haasis, T.I. and Liefner, I. (2019). "Reviewing the research on the internationalization of Chinese firms Thematic expansion, new impulses and potential future development", International Journal of Emerging Markets, Vol.14 No.1, pp.24-50.

He, Q., Tai-Leung Chong, T.and Shi, K. (2009). "What accounts for Chinese business cycle?", China Economic Review, Vol.20 No.4, pp.650-661.

He, Q., Du, J. and Xue, C. (2014). "What accounts for imperfect consumption risk sharing in China," Economic Research Journal, Nos1, pp. 4-16. (in Chinese)

He, SW., Khan, Z., Lew, YK. and Fallon, G. (2019). "Technological innovation as a source of Chinese multinationals' firm-specific advantages and internationalization", International Journal of Emerging Markets, Vol.14 No.1, pp. 115-133.

NBS (National Bureau of Statistics of China), 2019a, "Statistical Communiqué of the People's Republic of China on the 2018 National Economic and Social Development," Available from: http://www.stats.gov.cn/english/PressRelease/ 201902/t20190228_1651335.html.

NBS (National Bureau of Statistics of China), 2019b, "National Data," Available from: http://data.stats.gov.cn/easyquery.htm? $\mathrm{cn}=\mathrm{C} 01 /$.

Hevia, C. and Servén, L. (2018). "Assessing the degree of international consumption risk sharing”, Journal of Development Economics, Vol.134, pp.176-190.

Hicks, D. L. (2015). "Consumption volatility, marketization, and expenditure in an emerging market economy”, American Economic Journal: Macroeconomics, Vol.7 No.2, pp.95123.

Ho, C. Y., Ho, W. Y. A. and Li, D. (2015). "Intranational risk sharing and its determinants", Journal of International Money and Finance, Vol.51, pp.89-113.

Islamaj, E., and Kose, M. A. (2016). "How does the sensitivity of consumption to income vary over time? International evidence", Journal of Economic Dynamics and Control, Vol.72, pp.169-179.

Johannes, M., Lochstoer, L. A. and Mou, Y. (2016). "Learning about consumption dynamics", Journal of Finance, Vol.71 No.2, pp.551-600.

Kim, K., Lattemann, C., Park, B.Il. and Zhang, W. (2019). "New international business theories for China goes global? The importance of institutions, innovativeness and learning", International Journal of Emerging Markets, Vol. 14 No. 1, pp. 2-5.

Kose, M. A. and Riezman, R. (2001). "Trade shocks and macroeconomic fluctuations in Africa", Journal of Development Economics, Vol.65 No.1, pp.55-80.

Kydland, F. E. and Prescott, E. C. (1991). "Hours and employment variation in business cycle theory”, Economic Theory, Vol.1 No.1, pp.63-81.

Lai, J. T., So, E. P. K. and Yan, I. K. M. (2014). "Intergovernmental Fiscal Arrangements and 
Provincial Consumption Risk Sharing in China”, Emerging Markets Finance and Trade, Vol.50 No.3, pp.45-58.

Li, H., Shi, X. and Wu, B. (2016). "The retirement consumption puzzle revisited: Evidence from the mandatory retirement policy in China", Journal of Comparative Economics, Vol.44 No.3, pp.623-637.

Li, J., Zhang, D. and Su, B. (2019). "The impact of social awareness and lifestyles on household carbon emissions in China", Ecological Economics, Vol.160, pp.145-155.

Liu, Y., Shi, X. and Laurenceson, J. (2018). "Are China's exports crowding out or being crowded out? Evidence from Japan's imports”, China and World Economy, Vol.26 No.4, pp.1-23.

McKay, A. (2017). "Time-varying idiosyncratic risk and aggregate consumption dynamics", Journal of Monetary Economics, Vol.88, pp.1-14.

Nakamura, E., Sergeyev, D. and Steinsson, J. (2017). "Growth-rate and uncertainty shocks in consumption: Cross-country evidence”, American Economic Journal: Macroeconomics, Vol.9 No.1, pp.1-39.

Sahasranamam, S. and Raman, G.V. (2018). "Individual resources, property rights and entrepreneurship in China", International Journal of Emerging Markets, Vol.13 No.6, pp.1502-1521.

Santaeulàlia-Llopis, R. and Zheng, Y. (2018). "The price of growth: Consumption insurance in China 1989-2009”, American Economic Journal: Macroeconomics, Vol.10 No.4, pp.135.

Sapci, A. (2017). "Costly financial intermediation and excess consumption volatility", Journal of Macroeconomics, Vol.51, pp.97-114.

Tang, Q., Xia, Q. and Li, S. (2018) "An analysis of the consumption structure of Chinese urban households: 1995-2013”, Economic Research Journal, No.2, pp. 35-49. (in Chinese)

Tekin, İ.. (2017). "Does financial integration reduce consumption volatility and lead to consumption smoothing? A case of Latin America", Journal of Applied Economics and Business Research, Vol.7 No. 2, pp. 97-115.

Xu, X. (2008). "Consumption risk-sharing in China", Economica, Vol.75 No.298, pp.326-341.

Zhang, D., Lei, L., Ji, Q. and Kutan, A. M. (2019). "Economic policy uncertainty in the US and China and their impact on the global markets", Economic Modelling, Vol.79, pp.47-56.

Zhao, M. and Hsu, M. (2012). "China's economic fluctuations and consumption smoothing: Is consumption more volatile than output in China?", China Economic Review, Vol.23 No.4, pp.918-927. 